\title{
Enhancing Number System Knowledge to Promote Number Sense and Adaptive Expertise: A Case Study of a Second-Grade Mathematics Student
}

\author{
Cami C. Player* \& Jessica F. Shumway \\ School of Teacher Education and Leadership, Utah State University, Logan, UT \\ Student: cami.crump9@aggiemail.usu.edu* \\ Mentor:jessica.shumway@usu.edu
}

\begin{abstract}
Instruction for developing students' number sense is a critical area of research in mathematics education due to the role number sense plays in early mathematics learning. Specifically, number system knowledge-systematic relations among numerals and the use of number relations to solve arithmetic problems - has been identified as a key cognitive mechanism in number sense development. Number system knowledge is a component of number sense, and the researchers of this study hypothesize that it plays a critical role in second-grade students' understanding of relationships among numbers and adaptive expertise with mathematics problems. The purpose of this exploratory case study was to investigate the variations of an eight-year-old student's number system knowledge learning as she participated in an instructional treatment over nine weeks. The main research question of this study was: In what ways does a student struggling in mathematics develop number system knowledge during a nine-week period in her second-grade classroom as she engages in a number system knowledge instructional treatment? The case in this study was selected based on her low pretest score combined with her desire for making sense of mathematics. The data sources for this study were a number system knowledge assessment and student interviews. The analysis involved a multiple-cycle coding process that resulted in themes of adaptive expertise and the union of procedural and conceptual knowledge in mathematics instruction. The results suggest that this number system knowledge instructional treatment provided this case-study student to develop more pronounced adaptive expertise in solving mathematics problems. An in-depth analysis of how and why one struggling student develops number system knowledge during a nine-week instructional treatment within the context of her mathematics class provides exploratory evidence to help researchers and teachers develop and implement similar practices in elementary mathematics instruction.
\end{abstract}

\section{KEYWORDS}

Number Sense; Number System Knowledge; Mathematics Education; Whole Numbers and Operations; Elementary Education; Teaching and Learning; Case Study Research

\section{INTRODUCTION}

In mathematics education, number sense is defined in multiple ways because it is a complex construct of interconnected knowledge.1,2 Overall, number sense includes components such as understandings of quantities, numbers, and number system knowledge. The importance of number sense is reflected in the Common Core State Standards of Mathematics, in which connected understandings of foundational number concepts, such as number sense are an important theme in the document. 3,4 The focus of this article is on number system knowledge, which is one component of number sense. This article is about one eight-year-old student's development of number system knowledge, which is defined as knowledge of systematic relationships among numbers and the ability to use number relationships to solve arithmetic problems. ${ }^{5}$ This student participated in nine weeks of a number system knowledge instructional treatment and completed pretest, benchmark, and posttest assessments and assessment interviews targeting number system knowledge understandings and skills. The purpose of this exploratory case study was to investigate the variations of the student's number system knowledge learning during the instructional treatments.

\section{THEORETICAL FRAMEWORK}

Number sense view

Number sense requires a theoretical analysis because of the complexity of the construct. ${ }^{6}$ The number sense view provides a theoretical lens for understanding students' number sense development. The number sense view is the perspective that students' development of interconnected number concepts (as opposed to isolated skills) leads to more meaningful mathematical understandings. The number sense view explains that as reasoning with numbers improves (i.e., number system knowledge concepts), computational fluency with arithmetic problems improves. ${ }^{7,8}$ It provides a lens for understanding how number system knowledge influences, and is connected to, computational fluency, number line estimation, and problem solving. 


\section{Adaptive expertise}

Adaptive expertise is developed when children are stimulated to develop a strong framework of number relations and flexibly use these relations for computation. ${ }^{9}$ Adaptive experts are experts who apply their schemas in adaptive and tuned ways. ${ }^{10}$ Adaptive experts tend to use creative and innovative approaches to solving problems, rather than simply the routine expertise of speed, accuracy, and automaticity of solving familiar problems. Key characteristics of adaptive experts include understanding why procedures work, ability to invent new procedures, and success in applying their knowledge to new situations.

\section{Conceptual and procedural knowledge}

Adaptive expertise involves a combination of deep conceptual and procedural knowledge along with flexibility in thinking. Conceptual knowledge provides metaphors and representations that can serve as a source of adaptive expertise. Conceptual knowledge can be defined as the comprehension of mathematical concepts, operations, and relations, whereas procedural knowledge is defined as skill in carrying out procedures flexibly, accurately, efficiently, and appropriately. ${ }^{11}$ Conceptual knowledge acts as a foundation that enables procedural knowledge, and it supports retention. Students with conceptual understanding know more than isolated facts and methods. They understand why a mathematical idea is important and the kinds of contexts in which it is useful. An instructional implication is such that meaning must be built for procedural knowledge. Flexibility in mathematics strategies should be a result of the eventual integration of conceptual and procedural knowledge. ${ }^{12}$

Overall, the theories of number sense, adaptive expertise, and conceptual/procedural knowledge frame the methodology for this study and the interpretation of the results. These theories emphasize the complexity and interconnectedness of number knowledge, and thereby, provide a lens for understanding the variations in an eight-year-old student's number system knowledge.

\section{RESEARCH QUESTIONS}

The purpose of this study was to explore an eight-year-old student's variations in number system knowledge learning outcomes as she participated in an instructional treatment over nine weeks. The main research question of this study was: In what ways does a student struggling in mathematics develop number system knowledge during a nine-week period in her second-grade classroom as she engages in a number system knowledge instructional treatment? Specifically, the study looked at her variations on the target assessments and in her explanations of her reasoning in interviews:

What are the variations in her performance on the Number Sets test?

What are the variations in her performance on the number line tasks?

What are the variations in her performance on the computational fluency tasks?

What are the variations in her performance on the story problem tasks?

How is her number system knowledge reflected in her discussions during the instructional treatment?

\section{METHODS}

Design

The design for this study was an exploratory case study to investigate the variations of eight-year-old Sarah's (pseudonym) number system knowledge learning as she participated in an instructional treatment over nine weeks. ${ }^{13}$ This case study was part of a larger pilot project that developed and used a series of 27 teaching episodes aimed at improving second-grade students' number system knowledge. Sarah, along with her classmates, took a pretest, two benchmark tests, and a posttest assessing their number system knowledge. Sarah participated in an interview at each measurement point to further explain her reasoning and strategies for the solutions on these tests.

\section{Participant, setting, and materials}

Based on her number system knowledge pretest score of $29 \%$, Sarah was selected for further in-depth analysis because her score was in the bottom quartile of her class's scores. Sarah is a Caucasian female who does not qualify for free/reduced lunch, English Language Learner services, or special education services. She attended second-grade in a charter school in the western United States. She began the study at 7 years, 7 months of age. Sarah expressed great interest in mathematics and enjoyed participating in mathematical conversations. Sarah worked very methodically on mathematics tasks and was particular about the strategies she chose to use, wanting to successfully accomplish the tasks.

Sarah and her 23 second-grade peers participated in regular mathematics instruction, which included daily number sense warmups (i.e., the number system knowledge instructional treatment) prior to the mathematics lesson. The classroom teacher and a researcher (the second author) taught the 27 teaching episodes at the meeting area of the classroom. These teaching episodes took place three days per week during the first 15 minutes of the mathematics instructional period. Each teaching episode for the instructional treatment followed a fairly standard format of the Quick Images number sense routine, ${ }^{14}$ in which the teacher shows an image of a quantity for only a few seconds, then facilitates a discussion about how many objects the students saw and how they figured it out. For example, Figure 1 shows three of the Quick Images the teacher used during one session of the instructional 
treatment. Students individually considered the total amount, engaged in a pair-share discussion with a partner about how they figured out the total, and finally, the teacher facilitated a whole-class discussion about the various strategies for figuring out the total amount. The teacher purposefully connected students' responses with written numerals and equations to explicitly link the quantity with numerals and equations that represent it.

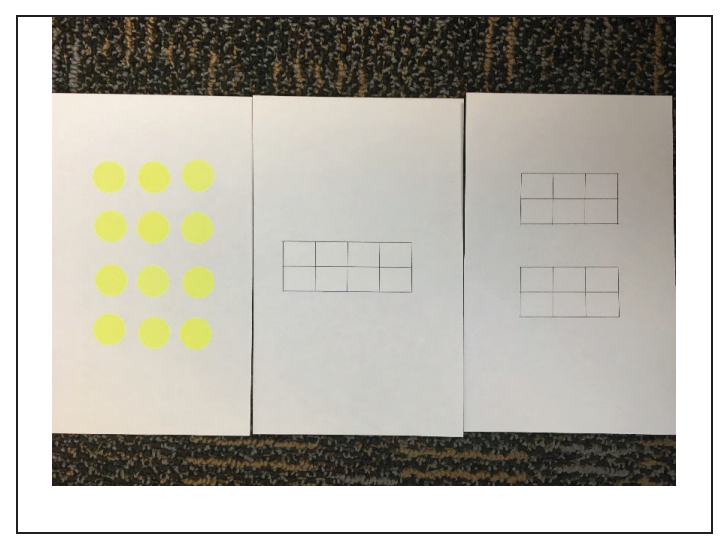

Figure 1. Three images of Quick Images quantities from one session of the instructional treatment.

This activity is theorized to activate students' number system knowledge in that students cannot possibly count each object. Instead, they rely on their sense of magnitude, subitizing abilities (i.e., perceptually recognize an amount without counting), and use relationships among numbers to figure out the total amount (e.g., benchmark numbers, part-whole ideas, and composing/decomposing amounts). Each teaching episode was characterized by a classroom discussion ${ }^{15}$ among students about the images of the quantities, eliciting number system knowledge ideas such as linking numerals to quantities, place value, decomposing and composing numbers, estimation, computation, and relationships among numbers. Each session included a symbolic representation linked with a non-symbolic representation. Since the sessions for the instructional treatment served as a warm-up activity, the classroom teacher continued to use her school-adopted curriculum materials as the main source for planning and teaching their regular mathematics lessons.

Data sources

Data were collected using number system knowledge assessments, clinical interviews, and classroom observations. Data were triangulated using these multiple sources.

Number System Knowledge Assessments. The number system knowledge pretest and posttest assessments included four sections: (1) The Number Sets Test (students match an anchor numerosity to a stimulus containing the same number of elements as the anchor), (2) The Number Line Tasks (students locate the position of seven different target numbers on a number line), (3) The Computational Fluency Test (students complete four minutes of single-digit addition and subtraction problems), and (4) Word Problem Situations (students solve four different word problems). The two benchmark assessments included different versions of the Computational Fluency and the Word Problems subtests. Percentages for each subtest were calculated and then averaged for an overall score on number system knowledge. Research indicates that these number system knowledge assessments better capture important variations in children's early mathematical development than performance on mathematics achievement tests. ${ }^{16}$

Clinical Interviews. The researchers used a semi-structured interview protocol asking Sarah about her strategies and reasoning for solving problems on the number system knowledge assessments. Sarah participated in four interviews (pretest, Benchmark 1, Benchmark 2, and posttest). The interviews were videotaped and portions of the interviews were transcribed for in-depth coding and analysis.

\section{Procedures}

The study occurred in three phases: 1) Pretreatment Phase, 2) Instructional Treatment Phase, and 3) Posttreatment Phase. During the Pretreatment Phase, researchers collected informed consent from the students' parents/guardians for participation in the study (IRB General \#7954). Once Sarah returned her signed informed consent, she completed the number system knowledge pretest and participated in a clinical interview about her mathematical reasoning and strategies. In the Instructional Treatment Phase, Sarah participated in the instructional treatment three times a week over nine weeks for a total of 27 sessions. Sarah was present at all 27 sessions. At weeks three and six of the instructional treatment sessions, Sarah completed the number system knowledge benchmark tests and again participated in clinical interviews for each benchmark test. Finally, during the Posttreatment Phase, Sarah completed the posttest and a final clinical interview. 


\section{Data analysis}

Quantitative data analysis involved visual analysis of measures of continual changes over time (e.g., graphs of means at each measurement point). Through this analysis, patterns and variations in the Sarah's number system knowledge were identified both holistically through the assessment score and discretely by subtest through the subtest scores. Analysis of the clinical interview data included open and axial coding for Sarah's written and verbal explanations of strategies for solving the mathematics problems. Beginning with open coding, the researchers analyzed the clinical interview video data and developed overarching concepts and categories, meaning general variations in Sarah's responses were coded. ${ }^{17} \mathrm{Next}$, the researchers used existing frameworks from the mathematics education literature to code Sarah's strategies with more specificity. ${ }^{18,19}$

\section{RESULTS}

The research questions for this study guided an investigation into Sarah's development of number system knowledge over a nineweek period of time. To answer the research questions, the results of her overall scores are presented and then the results are organized around Sarah's performance on the four subtests, along with her responses to interviews that addressed her use of strategies on each of the subtests. Due to the qualitative nature of the coding analysis, the major themes around her development of number sense and adaptive expertise are presented along within the results.

Overall test score variations

Sarah scored $29 \%$ on the number system knowledge pretest assessment and 38\% on the posttest assessment. Compared to her peers in the study, the mean pretest score for 23 students was $64 \%$, and the mean posttest score for 23 students was $66 \%$. The mean gain for students in Sarah's class was 2 percentage points. Sarah had a mean gain of 9 percentage points, which was the third highest gain in her class.

\section{Subtest variations}

Sarah's subtest scores varied in that she made pretest to posttest growth on all subtests except the target test for this study, the Number Sets Test in which her score decreased by over 10 percentage points. In addition, variations in her benchmark assessments across four measurement points for word problems and computational fluency alerted researchers to specific variations in her learning during the study, which were analyzed in-depth qualitatively. These results, disaggregated by subtest, provided more nuanced findings about Sarah's learning.

\section{Computational fluency subtest}

Sarah's computational fluency test scores increased from her pretest where she scored $18 \%$ to her posttest where she scored $23 \%$ (see Figure 2).

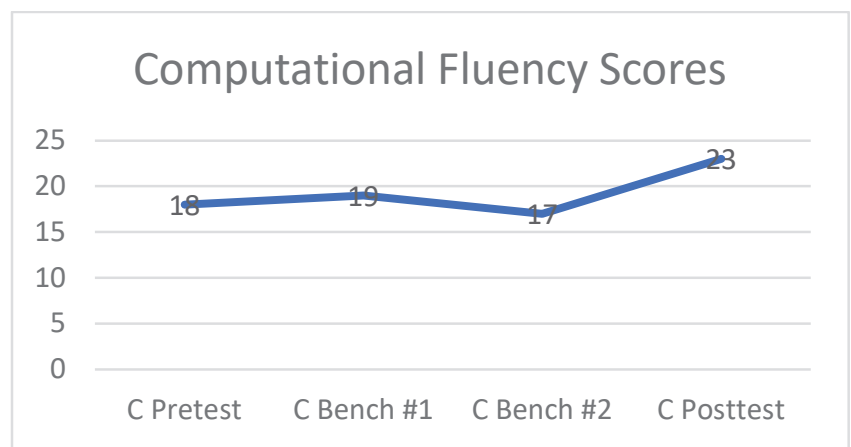

Figure 2. Line graph of Sarah's Computational Fluency subtest scores across measurement points.

Across measurement points, Sarah tended to use counting strategies most frequently, which is a lower level strategy. Sarah's interviews showed one to two more instances of reasoning strategies at each measurement point after the pretest and more instances of retrieval strategies on the posttest, which are more sophisticated strategies. Figure 3 highlights Sarah's strategy use over time. 


\begin{tabular}{|l|l|l|l|}
\hline Pretest: & Benchmark \#1: & Benchmark \#2: & Posttest: \\
Counting: $55 \%$ & Counting: 36\% & Counting: 45\% & Counting: $31 \%$ \\
Reasoning: $11 \%$ & Reasoning: $18 \%$ & Reasoning: $23 \%$ \\
Retrieval: $33 \%$ & Retrieval: $27 \%$ & Retrieval: $36 \%$ &
\end{tabular}

Figure 3. Frequency of Sarah's use of strategies on the Computational Fluency subtest.

Throughout the study, Sarah described the counting strategy as "her" counting strategy, showing favoritism for and comfort in this anchor strategy. As such she would count on from the larger number with basic addition problems. For example, she demonstrated how she might count on using tallies or her fingers as she counted on from 7 to find the answer to the problem $4+$ 7, as seen in her work on Benchmark 2 in Figure 4.

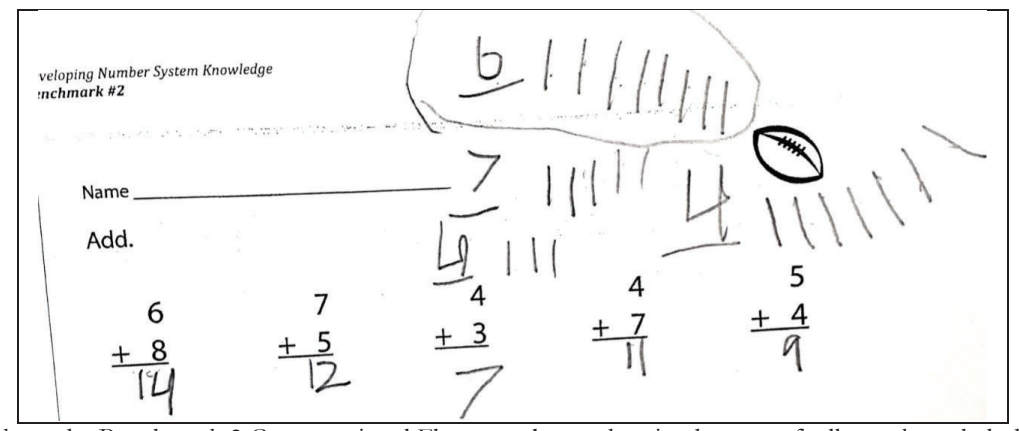

Figure 4. Sarah's written work on the Benchmark 2 Computational Fluency subtest, showing her use of tally marks to help her with her counting strategy.

When confronted with basic subtraction problems, Sarah would use her fingers or tallies more frequently to help her keep track of the counting sequence. When asked what she did when there was a number bigger than the number of fingers she had, she stated that she would use pencils or some other means to help her keep track as seen in the following transcript:

Interviewer: How did you know this one [Sarah]? Twelve minus eight is four?

Sarah: I had to use my fingers a lot on that one, and I just... was like... 12... and I, well, it was kind of hard and stuff because you don't have 12 fingers, and that one's a hard one sometimes, and if you can do a test at your desk I like to use pencils or something like that.

Interviewer: Okay, the last one I am going to ask you about is 18 minus 9.

Sarah: Um, that one... (laughs) it would be a hard one with my fingers too, like the first one. Um... because it's a really big number and stuff... but that's just that one.

Interviewer: Do you have a guess? What would your guess be?

Sarah: Probably... 9 or 7 or something. I don't know.

Interviewer: That's a good guess! Why would that be your guess?

Sarah: Well... it's just kind of some really high numbers, and so it would still be pretty high numbers, and yeah.

This pattern was seen to be used more frequently in the pretest where she used counting strategies on five of the nine computations she was interviewed about. When interviewed about the Benchmark 1 test, while Sarah still relied heavily on "her" counting strategy, she began to use more reasoning strategies where she would use patterns and relationships among numbers to invent reasoning strategies to solve unfamiliar problems. For instance, when confronted with the problem $9+2$, she took one from the two, and gave it to the nine in order to make ten, then added one more. The use of these strategies demonstrates a developing maturity and flexibility in Sarah's number sense. On the Benchmark 1 test, Sarah began to demonstrate more flexibility with her number sense development as she used counting, reasoning, and retrieval strategies with the same frequency. This progression was also seen in the results of Sarah's Benchmark 2 test. It was noted that Sarah tended to use more retrieval strategies where she was able to efficiently, appropriately, and adaptively produce sums and differences from a memory network. This shift in Sarah's thinking was seen with the problem 5+6 during her interviews across four measurement points (see Figure $5)$. 


\begin{tabular}{|c|c|c|c|}
\hline Pretest & Benchmark 1 & Benchmark 2 & Posttest \\
\hline $\begin{array}{l}\text { Interviewer- "So this one, you almost } \\
\text { got to that one, } 5+6 \text {, how do you figure } \\
\text { that out?" }\end{array}$ & $\begin{array}{l}\text { Interviewer- "How about } 5+6 \text { ? How } \\
\text { would you figure that out?" }\end{array}$ & $\begin{array}{l}\text { Interviewer- "What's 5+6?" } \\
\text { Sarah- "Well... um... I would do my }\end{array}$ & $\begin{array}{l}\text { Interviewer- "Now, this one you didn't } \\
\text { solve, } 5+6 \text {, bow would you solve that } \\
\text { now? }\end{array}$ \\
\hline $\begin{array}{l}\text { Sarah- 'Well, usually what I do is my } \\
\text { counting strategy... and I just go } 6,7,8 \text {, } \\
9,10,11 . . \text { and that stuff, but } \\
\text { sometimes what you have to do is you } \\
\text { have to if it's bigger than, if it's like a } \\
\text { two numbers, and you have to put one } \\
\text { up or something.. and yeah I just knew } \\
\text { that and so I was about going to answer } \\
\text { that one, but not quite." }\end{array}$ & $\begin{array}{l}\text { Sarab- "Well, I would probably do my } \\
\text { strategy of } 6 \ldots 7,8,9,10,11 \ldots \text { ".. } \\
\text { Interviewer- "Nice, where you're } \\
\text { counting up from six?" } \\
\text { Sarab- "Yes." }\end{array}$ & $\begin{array}{l}\text { counting strategy, and go } \\
6,7,8,9,10,11 \ldots \text { and then I know it's } \\
\text { 11." }\end{array}$ & $\begin{array}{l}\text { Sarah- 'Um, well, I'd know it's } 11 \text {, } \\
\text { there's a few ways. Um, I know that } \\
5+4 \text { is 9, add on two more would be } \\
\text { 11. Um, and then I know that } 4+6 \text { is } \\
\text { 10, but if I add on one more it would } \\
\text { be 11. " }\end{array}$ \\
\hline
\end{tabular}

Figure 5. Sarah's verbal responses explaining her strategies for solving $5+6$ across four measurement points.

On the pretest, Benchmark 1 and Benchmark 2, Sarah would count on from six, using her fingers to keep track of what she had counted. On the posttest, however, she identified two new strategies she might use to solve the problem. This instance represents a breakthrough in Sarah's thinking as she moved to more sophisticated strategies and the idea that there are multiple ways to solve the problem.

While Sarah demonstrated this shift in understanding, she still held to her counting strategies in order to solve several of the computations. These strategies are something that Sarah saw as being reliable and familiar, and she trusted them to get her to the correct answer. This reliance on the counting strategies was still manifest in Sarah's posttest data where she continued to develop more retrieval strategies, yet held to those counting strategies she trusted. The counting strategies showed up more frequently in subtraction problems, which demonstrate Sarah's developing understanding of the properties of subtraction as she worked to develop more adaptive expertise in this unfamiliar area.

Word problems subtest

Figure 6 shows Sarah's test scores for the Word Problem subtest across the four measurement points. While the scores show an increase from $25 \%$ to $75 \%$ and a decrease to $50 \%$, her interviews explain or rival the trends in the test scores.

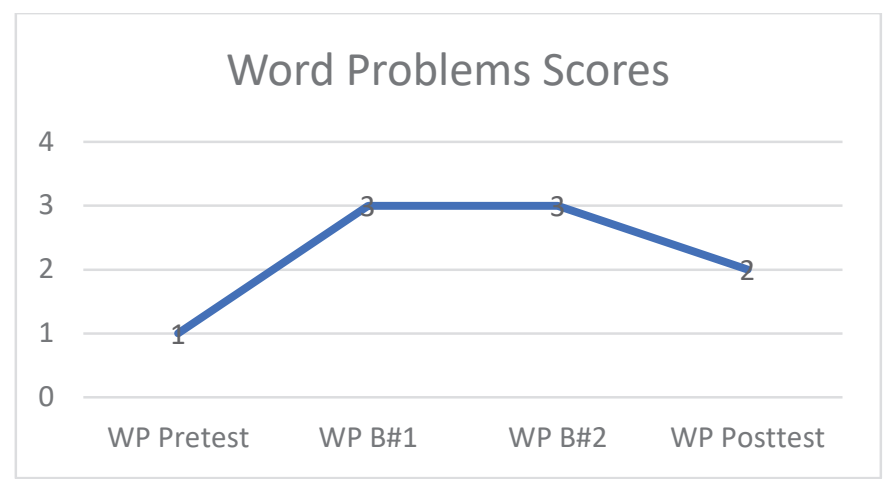

Figure 6. Line graph of Sarah's Word Problem subtest scores across measurement points.

On Sarah's pretest she frequently used a direct modeling strategy, the most basic strategy in our coding framework. Having concrete representations of the items addressed in the word problems helped Sarah to visualize the task and better find solutions. For example, Figure 7 shows that on the pretest, Sarah drew three boxes to represent each bag of cookies. She then drew 15 circles in each bag to represent each cookie in the bag, which are organized in rows of 5. 


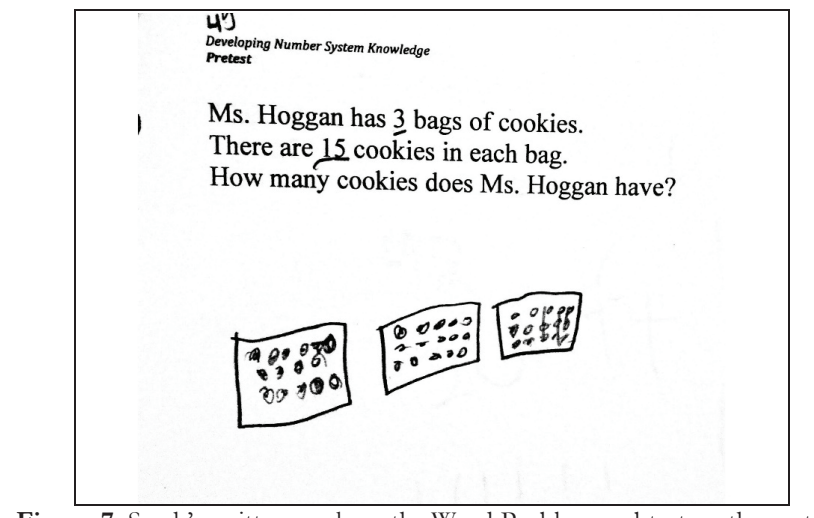

Figure 7. Sarah's written work on the Word Problems subtest on the pretest.

Sarah's counting strategies, on the Word Problems subtest, are slightly more sophisticated than the direct modeling strategies. One distinct instance where Sarah's use of counting strategies was highlighted was on Benchmark 1, as seen in Figure 8. Sarah started by writing a three, then proceeded to count up to twelve using tally marks to keep track. She eventually got to twelve and counted each tally mark, providing her with the answer of nine. This problem was one of many instances where Sarah relied on counting strategies to develop an answer.

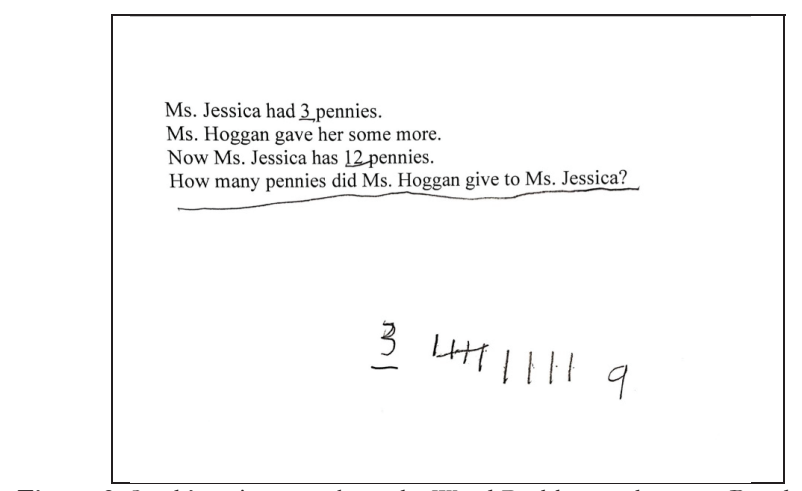

Figure 8. Sarah's written work on the Word Problems subtest on Benchmark 1.

While not apparent in the test scores, the interviews elucidate a shift in Sarah's strategies at Benchmark 2. By Benchmark 2, Sarah began to move away from the direct modeling strategies and toward more counting and reasoning strategies. Sarah began to recognize that it was not necessary to physically construct and count the two sets described in a problem, and could see that there were more efficient methods. For example, during the Benchmark 2 interview, Sarah was asked to solve the following problem shown in Figure 9.

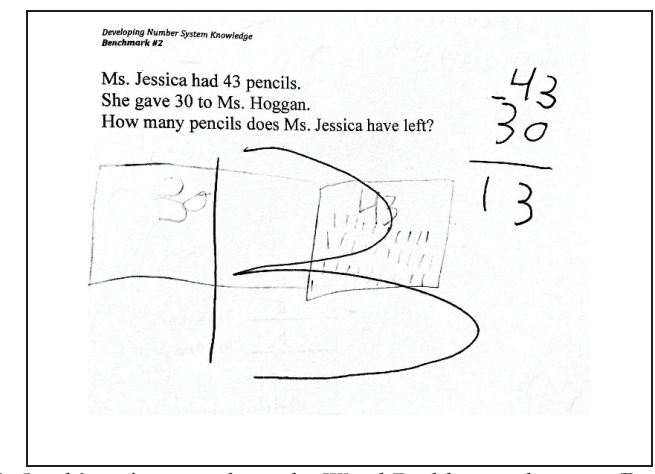

Figure 9. Sarah's written work on the Word Problems subtest on Benchmark 2.

The following conversation took place around her work in Figure 9:

Interviewer: What about this one? I saw you used an equation... you started a picture, but then what did you do? 
Sarah: Well, I was gonna do a picture, but I knew it would take longer and be harder. So, I did it with just that way because those ways are easier for me, and I got thirteen.

Interviewer: How did you get thirteen on this equation?

Sarah: Well, I took three, I did three take away zero, and it was still three. Then I took four away from three and... took three away from four and it was one.

The realization that there are more efficient strategies seemed to be monumental as Sarah began to complete the tasks with more accuracy. This transition from a conceptual to a more procedural understanding occurred after six weeks of participation in the Number System Knowledge instructional treatment. Sarah tended to use tally marks in order to keep track of the addends when needed, but was able to use invented strategies on $50 \%$ of the tasks on Benchmark 2.

This shift to more efficient strategies continued to develop through the next couple weeks as Sarah took her posttest and had only one instance where she used her counting strategy, but also used both invented strategies and the algorithm. On the multiplication problem in Figure 10, Sarah drew tallies to represent the cookies in each bag. She counted the tallies by five, and stated that there were $30+15$ tallies. However, as she made the shift to creating an equation to represent her picture, she had written $20+15$, coming to an incorrect answer of 35 .

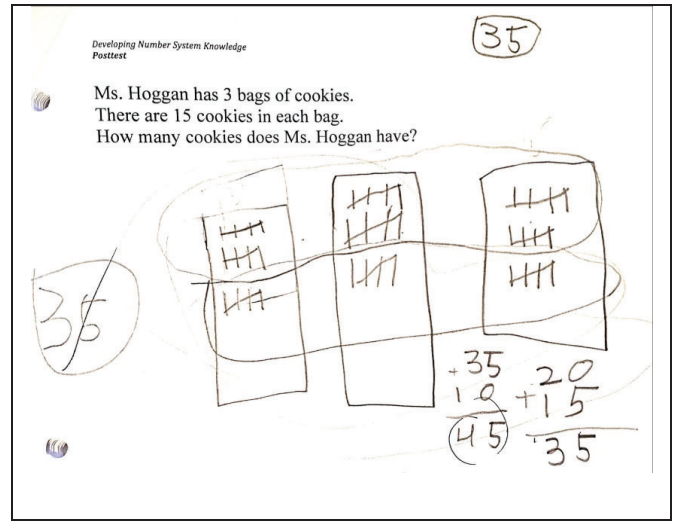

Figure 10. Sarah's written work on the Word Problems subtest on the posttest.

During Sarah's posttest interview, she was able to successfully see where she had made the mistake and revised her equation bringing her to the correct answer. This instance demonstrates Sarah's gradual shift from using direct modeling and counting strategies, to a more sophisticated use of invented strategies and algorithms. It is important to note that this shift is seen through the mathematical conversations in the interviews, however, the shift is hidden by the test scores. The test scores show a slight increase from the pretest but a decrease from Benchmark 2 to the posttest. This is an instance where the test scores and the interviews diverge. The counting strategies provided Sarah with a foundation upon which she built her number sense, and as she became more comfortable with her number sense capabilities, she trusted her ability to use more efficient strategies.

\section{Number line estimation subtest}

While there were four measurement points for the computation and word problems, the Number Line Estimation tasks were assessed only at the pretest and posttest. Sarah's score improved from 20\% to 40\%. Figure 11 shows her improved accuracy from the pretest to the posttest for the number 61 .

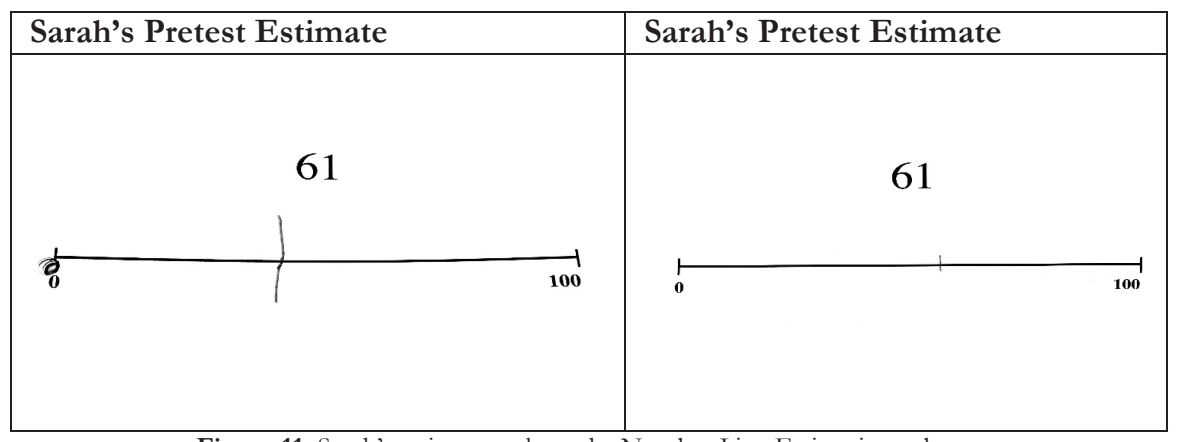

Figure 11. Sarah's written work on the Number Line Estimation subtest. 
In contrast, her interviews on the tasks were coded as a regression from measurement strategies to counting strategies. While regression was coded, Sarah's language as she described why a number belongs in her selected location on the number line showed more precision and attention to place in relation to numbers. On Sarah's pretest, she tended to look at the number line more holistically. She generally tried to use the benchmark numbers in order to orient herself. However, the benchmark numbers she chose to use were not always the most efficient, as seen in the following excerpt from her pretest interview:

Interviewer: How did you know that 8 belongs there on the number line?

Sarah: Well, I just thought that it was really less than 100, so I just put it kind of right there. Because I knew it was pretty less and not so much.

Interviewer: How did you know 84 belongs there?

Sarah: Well, I just knew that 8 was down here and it was kinda more ahead so I just put it there.

It is interesting to note that Sarah did not use any counting strategies on the number line on this particular test, but used her best estimate based on the numbers she knew. She did not use tick marks or any other method of keeping track that you might suspect she would choose to use given her choice of strategies on the other tasks involved in the assessment.

On the posttest, however, Sarah chose to use more counting strategies, yet she used this as a way of checking herself as seen in the following excerpt from her posttest interview:

Interviewer: How did you know 8 belongs there?

Sarah: Um, well, I just went like lower, I had it go a little lower, like a little more by the zero because...like... it could be like 1,2,3,4,5,6,7,8 [pointing to imaginary tick marks]...or something...and so like, I just do it in a place that I would guess.

She continued to use the same strategy as she placed the 84 :

Interviewer: How did you know that 84 belongs there?

Sarah: Because I knew that 80 would be more by 100 than it would be by 0 , so I put it a little closer over here, but I still remembered that we had 85, 86, 87, 88, 89, 90, 91, 92, 93, 94, 95, 96. 97, 98. 99. 100 [pointing to imaginary tick marks]. So, I still made sure there was some space.

On the posttest, Sarah used more logical benchmark numbers to know where to place the numbers, but relied on a counting strategy to verify that she had placed the number in the correct location on the number line. This merging of test score, holistic coding, and axial coding analyses helped to explain specific and subtle learning growth on the Number Line Estimation subtest.

\section{Number sets subtest}

This particular test was the targeted test for this study because it most directly aligned with the instructional intervention.

Researchers hypothesized students would improve the most on this subtest. It is curious, then, that Sarah's test scores went down on this subtest, where progress was seen in all other subtest areas. Her scores on the number sets subtest decreased from $51 \%$ to $40 \%$ (in both cases, the lowest test score among her peers). This difference could be contributed to the piloting of the test in this study and the varied time allotment given to students on each test (90 seconds on the pretest, 60 second on the posttest). With less time on the posttest, it was difficult to compare the scores from pretest to posttest. The other aspect to consider was that Sarah may have spent more time being thoughtful about her solutions. Her interview data showed that she matured in her mathematical thinking as her methods were more efficient. There was also evidence that Sarah developed more flexibility when working with different number combinations. For example, in Figure 12, Sarah's posttest response showed improvement in three ways. She attached an equation to the quantity, stated a sum, and showed more flexibility in her thinking (e.g., "there's a few ways").

\begin{tabular}{|l|l|l|l|}
\hline \multicolumn{2}{|l|}{ Assessment Item } & \multicolumn{1}{|c|}{ Pretest } & \multicolumn{1}{c|}{ Posttest } \\
\hline \multicolumn{1}{|l|}{} & It has two and then two and then one. & $\begin{array}{l}\text { So... there's a few ways. So, 2 plus 2 } \\
\text { equals 4 plus 1 equals 5. Or, I could put } \\
\text { this one here [pointing to the single dot } \\
\text { and moving it to the box with 2 dots] } \\
\text { and make 0, and 2 plus 3 equals 5. }\end{array}$ \\
\hline
\end{tabular}

Figure 12. Sarah's interview from pretest to posttest on one Number Sets subtest item.

Sarah used counting strategies much less frequently on the number sets test (particularly on the posttest) when compared to her strategy choices on the pretest. On the pretest, however, she alluded to having used her counting strategy as seen in the following transcript from her pretest interview:

Interviewer: When you were solving these problems, you were looking for groups that add up to five, or groups that add up to nine, do you remember that? 
Sarah: Yes.

Interviewer: Did you have a strategy for figuring it out?

Sarah: Well, what I really did is if there's one that was really hard, I just kind of like count the biggest number and then count the like just like say $5 . .$. like say 4 , and then 1 , and that's technically what I do. Then ones like 4 and 1 I kind of know 5 and 0 I kind of know pretty much but yeah...

It was evident that when she became unsure of the answer, she reverted to her counting strategies because she knew that these strategies were something she could count on. Sarah's continued use of counting strategies even into the posttest revealed her reluctance to make the shift to the symbolic realm and trust her ability to recognize certain combinations. For example, in Figure 13, her response from pretest to posttest on the symbolic problem 7 and 2 showed her use of the same strategy, but emerging understanding that there were other ways to figure it out.

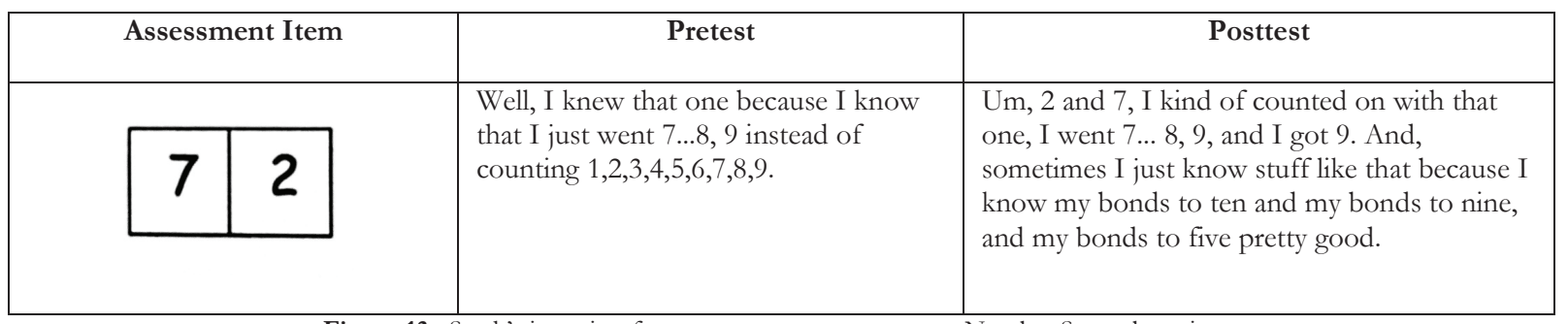

Figure 13. Sarah's interview from pretest to posttest on one Number Sets subtest item.

Even though Sarah stated that she did know bonds to nine and just "knows stuff like that," she still insisted on using a counting strategy with that particular problem. Counting was a strategy she was comfortable with, and the data reveal that she was hesitant to move to a retrieval strategy.

On the posttest, a theme developed where Sarah would manipulate the quantities in her mind in such a way that she could create a shape or a number that she could work with more easily. Sarah was able to successfully subitize many of the numbers, and those she could not, she would use spatial reasoning to develop an answer. Sarah became much more playful with the combinations of symbols and quantities and demonstrated more flexibility with her strategies as seen in the following transcript:

Interviewer: Did you kind of have a general strategy for figuring some of these out, or did it depend on the numbers? Sarah: Well, it kind of depended, but with like this first one, and some of these ones... I just technically like put that one in the middle and I made it look like a dice, and then made this look like a zero, and stuff like that.

Interviewer: So you kind of move the dots around in your head?

Sarah: Yeah, but I also kind of knew them like that, but there were some other ways that I did it too.

This creativity and use of spatial reasoning represented a significant development in Sarah's thinking as she became more sophisticated in her number system knowledge. She was able to use compensation strategies and played around spatially with the dots to make the problem easier to solve. In Sarah's posttest interview, she used the word 'count' much less frequently, which also showed her building trust in the new strategies she developed. Although the quantitative data show a decrease in Sarah's understanding, the qualitative data demonstrated positive nuanced shifts in her learning.

\section{DISCUSSION}

The purpose of this exploratory case study was to examine one eight-year-old student's development of number system knowledge during a nine-week instructional treatment. Results showed that Sarah increasingly put her number sense to work and developed more pronounced adaptive expertise in solving mathematical problems as evidenced in a combination of her test scores and explanations for strategies in her interviews. Sarah became more creative and flexible with her reasoning strategies across all assessment areas. Initially, Sarah relied on counting strategies to solve computation problems, word problems, and number sets problems. Over time, however, she began to demonstrate confidence in her ability to flexibly manipulate numbers and displayed the ability to think critically when faced with challenging problems. Sarah used more sophisticated strategies, demonstrated more efficiency and innovation, and showed awareness of strategies beyond her comfort-level counting strategies.

The instructional treatment in this study aimed to marry conceptual and procedural knowledge and provided a conceptual foundation upon which procedural knowledge could be based upon by linking numerals to quantities. This basis opened avenues through which Sarah could develop flexibility in her thinking and invent her own strategies. The data showed that Sarah not only developed a stronger conceptual basis, but also moved towards more fluent procedural processing where she was able to subitize with more automaticity and begin to use retrieval strategies. 
Psychologists and educators have long debated how number combinations are learned and how to best promote fluency. The results illuminated by this study are consistent with studies on adaptive expertise with basic addition and subtraction combinations in that conceptual learning plays a key role in developing number sense. ${ }^{20}$ Focusing on structure (underlying patterns and relations) makes the learning, retention, and transfer of any large body of factual knowledge more likely than memorizing individual facts by rote. The instructional treatment in the study provided students the opportunity to identify patterns and relations within numbers in an effort to extend their knowledge base of early number sense.

\section{CONCLUSIONS}

The results of the study provide an opportunity to understand number system knowledge in the context of one student's learning. There is consistent evidence that children's symbolic number system knowledge at the beginning of formal schooling predicts concurrent and later mathematics achievement. ${ }^{21}$ This evidence supports the need for focused instructional treatments at the early grade levels in order to secure future mathematics success.

The theory and knowledge gained through this study could influence the development of effective instructional practices and extend the knowledge base of early number sense. It highlights the need for teachers to implement number sense-based instructional practices as they enhance the learning, retention, and transfer of any large body of factual knowledge, more so than memorizing facts by rote. ${ }^{22}$ As seen in this case study, when teachers implement instructional practices that marry both procedural and conceptual strategies by linking numerals to quantities, students develop number sense and adaptive expertise. While it is important for students to develop procedural fluency with basic mathematical computations, it is also important that they have a conceptual base upon which procedural knowledge is built. Conceptual knowledge can lead to advances in procedural knowledge and ultimately contributes to the development of adaptive expertise through flexibility in self-constructed strategies.

\section{ACKNOWLEDGEMENTS}

The authors thank the case study student and classroom teacher that participated in the study.

\section{REFERENCES}

1. Berch, D. B. (2005). Making sense of number sense: Implication for children with mathematical disabilities. Journal of Learning Disabilities, 38(4), 333-339.

2. Locuniak, M. N., \& Jordan, N. C. (2008). Using kindergarten number sense to predict calculation fluency in second grade. Journal of Learning Disabilities, 41(5), 451-459.

3. Common Core State Standards Initiative. (2010). Common core state standards for mathematics. Retrieved from http:// corestandards.org

4. Confrey, J., \& Krupa, E. (2010). Curriculum design, development, and implementation in an era of common core state standards: Summary report of a conference. Arlington, VA. Retrieved from http://www.mathcurriculumcenter.org/reports_ research.php

5. Geary, D. C., Hoard, M. K., Nugent, L., \& Bailey, D. H. (2013). Adolescents' functional numeracy is predicted by their school entry number system knowledge. PLOS ONE 8(1): e54651. doi:10.1371/journal.pone.0054651

6. Greeno, J. G. (1991). Number sense as situated knowing in a conceptual domain. Journal for Research in Mathematics Education, 22, 170-218. doi:10.2307/749074

7. Baroody, A. J., \& Rosu, L. (2006, April). Adaptive expertise with basic addition and subtraction combinations: The number sense view. In A. J. Baroody \& J. Torbeyns (Chairs), Developing adaptive expertise in elementary school arithmetic. Symposium conducted at the annual meeting of the American Educational Research Association, San Francisco, CA.

8. Baroody, A. J., Feil, Y., \& Johnson, A. R. (2007). An alternative reconceptualization of procedural and conceptual knowledge. Journal for Research in Mathematics Education, 38(2), 115-131.

9. Verschaffell, L., Luwel, K., Torbeyns, J., \& Van Dooren, W. (2009). Conceptualizing, investigating, and enhancing adaptive expertise in elementary mathematics education. European Journal of Psychology of Education, 24: 335. https://doi.org/10.1007/BF03174765

10. Hatano, G. \& Oura, Y. (2003). Reconceptualizing school learning using insight from expertise research. Educational Researcher, 32(8), 26-29.

11. National Research Council. (2001). Adding it up: Helping children learn mathematics. J. Kilpatrick, J. Swafford, and B. Findell (Eds.). Mathematics Learning Study Committee, Center for Education, Division of Behavioral and Social Sciences and Education. Washington, DC: National Academy Press.

12. Haapasalo, L. (2003). The conflict between conceptual and procedural knowledge: Should we need to understand in order to be able to do, or vice versa. Proceedings on the IXX Symposium of the Finnish Mathematics and Science Education Research Association, University of Joensuu, Bulletins of the Faculty of Education. Vol. 86.

13. Yin, R. K. (2014). Case study research: Design and methods, $5^{\text {th }}$ ed. Thousand Oaks, CA: Sage.

14. Shumway, J. F. (2011). Number sense routines: Building numerical literacy every day in grades K-3. Portland, ME: Stenhouse. 
15. Chapin, O’Conner, \& Anderson, 2009,

16. Geary, D. C., Hoard, M. K., Nugent, L., \& Bailey, D. H. (2013). Adolescents' functional numeracy is predicted by their school entry number system knowledge. PLOS ONE 8(1): e54651. doi:10.1371/journal.pone.0054651

17. Miles, M. B., \& Huberman, A. M. (1994). An expanded sourcebook: Qualitative data analysis (2nd ed.). Thousand Oaks, CA: Sage.

18. Carpenter, T. P., Fennema, E., Franke, M. L., Levi, L., \& Empson, S. B. (1999). Children's mathematics: Cognitively guided instruction. Portsmouth, NH: Heinemann.

19. Diezman \& Lowrie, 2006

20. Baroody, A. J., \& Rosu, L. (2006, April). Adaptive expertise with basic addition and subtraction combinations: The number sense view. In A. J. Baroody \& J. Torbeyns (Chairs), Developing adaptive expertise in elementary school arithmetic. Symposium conducted at the annual meeting of the American Educational Research Association, San Francisco, CA.

21. Geary, D. C. (2011). Cognitive Predictors of Achievement Growth in Mathematics: A 5-Year Longitudinal Study. Developmental Psychology, 47(6), 1539-1552.

22. Jordan, N.C., Glutting, J., \& Ramineni, C. (2010). The importance of number sense to mathematics achievement in first and third grades. Learning and Individual Differences, 20, 82-88.

\section{ABOUT STUDENT AUTHOR}

Cami C. Player graduated with a BA in Elementary Education from the School of Teacher Education and Leadership at Utah State University in 2017. She worked as an Undergraduate Research Assistant for the Early Math Research Group (EMRG) on the project "Developing Number System Knowledge: An Exploratory Study of Visual Quantities Instructional Tasks" during her senior year. She is currently a $5^{\text {th }}$ grade teacher at Woodruff Elementary School in Logan, Utah, and intends to pursue a master's degree in education.

\section{PRESS SUMMARY}

Instruction for developing students' number sense is a critical area of research in mathematics education due to the role number sense plays in early mathematics learning. Specifically, number system knowledge-systematic relations among numerals and the use of number relations to solve arithmetic problems - has been identified as a key cognitive mechanism in number sense development. The purpose of this exploratory case study was to investigate the variations of an eight-year-old student's number system knowledge learning as she participated in an instructional treatment over nine weeks. An in-depth analysis of how and why one struggling student develops number system knowledge during a nine-week instructional treatment within the context of her mathematics class provides exploratory evidence to help researchers and teachers develop and implement similar practices in elementary mathematics instruction. 